\title{
Familial Immune Thrombocytopenia. Report of 16 Cases and Litera- ture Review
}

\author{
Núria Pujol-Moix ${ }^{1,2 *}$, Blanca Jimenez ${ }^{2}$, Eduardo Muñiz-Diaz ${ }^{3}$, Manel Roca ${ }^{4}$, Joan Carles Souto ${ }^{2,5}$ \\ 'Medicine Department, Unitat Docent Sant Pau, Universitat Autònoma de Barcelona, Spain \\ ${ }^{2}$ Institute of Biomedical Research (IIB-Sant Pau), Barcelona, Spain \\ ${ }^{3}$ Division of Immunohematology, Banc de Sang i Teixits de Catalunya, Barcelona, Spain \\ ${ }^{4}$ Nuclear Medicine Department, Hospital Universitari de Bellvitge, L'Hospitalet de Llobregat, Spain \\ ${ }^{5}$ Unitat d'Hemostàsia i Trombosi, Hospital de la Santa Creu i Sant Pau, Barcelona, Spain
}

Article Info

\section{Article Notes}

Received: October 7, 2018

Accepted: November 28, 2018

\section{*Correspondence}

Dr. Núria Pujol-Moix, Unitat Docent Sant Pau. Universitat

Autònoma de Barcelona Sant Antoni M. Claret, 167, 08025-Barcelona, Spain; Email: npujolmoix@gmail.com

(c) 2018 Pujol-Moix N. This article is distributed under the terms of the Creative Commons Attribution 4.0 International License.

\section{Keywords}

Familial

Immune thrombocytopenia

Autoimmune disorder

Antiplatelet antibodies

Platelet survival

Genetic thrombocytopenia
Abstract

Immune thrombocytopenia (ITP) is an acquired disorder that generally occurs in sporadic individuals, but a few patients are grouped in families. The aims of the present study were: 1 ) to perform a retrospective descriptive study of a series of patients with familial ITP, and 2) to perform a literature review on familial ITP.

We studied 16 ITP patients, from 8 families, selected by using the general established exclusion criteria as well as at least one of the following additional positive criteria: the finding of autoantibodies on the platelet surface, a short platelet survival in the kinetic study, or a clear therapeutic response to immunosupressors or splenectomy. Moreover, we studied 60 patients with familial ITP previously reported in the literature, selected by using the same diagnostic criteria as for our patients.

The patient's characteristics of familial ITP were not substantially different from those of sporadic ITP patients. The small number of patients reported in the literature suggests that, familial ITP has been underdiagnosed. We recommend considering the possible diagnosis of familial ITP when a familial thrombocytopenia has no demonstrable genetic cause, especially if there are other autoimmune disorders in the family. Moreover, to obtain a true diagnosis in these families we recommend applying the additional positive criteria mentioned above besides the exclusion diagnostic criteria.

\section{List of Abbreviations}

ITP = immune thrombocytopenia

Ig = immunoglobuin, immunoglobulins

$\mathrm{AD}=$ autoimmune disorder, autoimmune disorders

\section{Introduction}

Immune thrombocytopenia (ITP), also known as idiopathic thrombocytopenic purpura, is an immune-mediated acquired disease characterized by transient or persistent decrease of the platelet count and, depending upon the degree of thrombocytopenia, increased risk of bleeding ${ }^{1}$. Antibodies reacting against platelet glycoproteins can mediate destruction of platelets by the monocytemacrophage system as well as suppress megakaryocyte proliferation and maturation ${ }^{2}$. Although ITP is an acquired disorder that generally occurs in sporadic individuals, some cases have been described to occur in families. In 2011, the PARC registry on ITP (Pediatric and 
Adult Registry of Chronic ITP) reported that a small number of patients with ITP had relatives with thrombocytopenia and probably some of them were ITP ${ }^{3}$.

The Platelet Pathology Unit of the Hospital de la Santa Creu i Sant Pau (Barcelona, Spain), created in 1990, is a clinical and laboratory center specialized in the diagnosis and management of patients with uncommon platelet disorders, mainly of genetic origin. A large number of families with thrombocytopenia of uncertain origin were referred to the Unit and most of them were diagnosed with different types of platelet genetic disorders. However, a few of these families did not fit with any genetic disorder, instead they fulfilled the criteria for familial ITP defined as the presentation of ITP in 2 or more members of a family.

The aims of the present study were: 1) to perform a retrospective descriptive study of a series of patients with familial ITP, and 2) to perform a literature review on familial ITP.

\section{Methods}

\section{Selection of the patients and families}

From the database of the Platelet Pathology Unit of the Hospital de la Santa Creu i Sant Pau, over 28 years, we studied the medical records of patients and families that presented familial ITP. The criteria applied were:

The diagnosis of ITP required that the platelet count was lower than normal $\left(<150 \times 10^{9} / \mathrm{L}\right)$ and that there was no other known causes of thrombocytopenia such as folate or vitamin $B_{12}$ deficiency, bone marrow hypoplasia or aplasia, hepatopathy and/or hypersplenism, disseminated intravascular coagulation, thrombotic thrombocytopenic purpura, alloimmune, genetic or drug-related thrombocytopenia, HIV infection, or any type of primary immunodeficiency or immune dysregulation disorder. In addition to the exclusion criteria, at least one of the following positive diagnostic criteria was required: 1) the finding of autoantibodies fixed on the platelet surface, 2) an isotopic platelet kinetic study demonstrating a shorter than normal platelet survival, or 3) a clear therapeutic response to corticosteroids, intravenous immunoglobulins (Ig) or other immunosuppressors, or splenectomy. If the ITP was associated with any other autoimmune disorder (AD), the patient was not excluded from the study. Instead, the $\mathrm{AD}$ was used to define the patient's characteristics.

The diagnosis of familial ITP required that at least 2 family members fullfilled the criteria for ITP. If other family members had thrombocytopenia but the data were not suficient to insure the diagnosis of ITP, these patients were recorded but not included in the study.

Our study was performed according to the Declaration of Helsinki and the study protocol was approved by the
Institutional Review Board of the Hospital de la Santa Creu i Sant Pau.

\section{Clinical and laboratory data}

The demographic, clinical, and laboratory data of all patients were extracted from the medical records. The electronic platelet counts were performed using carefully calibrated electronic cell counters; however, since the patients were studied over several years, different cell counters were used. The microscopic platelet counts were performed by means of a Neubauer chamber. The observation of platelets by light microscopy was performed using blood films obtained directly (without anticoagulant) and stained with May-Grünwald-Giemsa. Platelet aggregates and/or giant platelets (these platelets of more than $4 \mu \mathrm{m}$ in diameter) were evaluated.

The platelet serologic tests were performed with the direct and indirect immunofluorescence tests (eluate and serum studies) ${ }^{4}$. These tests provided evidence of autoantibodies bound to the platelet membrane and its Ig type. Also, variants of these tests revealed if there were cryptoantibodies and if these were EDTA-dependent ${ }^{5}$. The lymphocyte counts, the serum immunoglobulin levels and the laboratory autoimmune markers were recorded also.

\section{Literature review on familial ITP}

The combination of the concepts "immune thrombocytopenia" and "familial" was searched in the PubMed database from the beginning until July 2018. To locate "immune thrombocytopenia", we searched the terms: immune- autoimmune- or idiopathic- thrombocytopenia, immune- autoimmune- or idiopathic- thrombocytopenic purpura, ITP, Werlhof, purpura hemorrhagica, platelet autoantibodies, Evans syndrome, antiphospholipid syndrome, and antiphospholipidic syndrome. For the search related to "familial", we used the terms: familial, family, hereditary, siblings, relatives, sibship, and twins. All the articles cited as familial ITP (or their synonyms) in the published articles, were included also in our review. To accept the diagnosis of familial ITP in the published articles, 2 or more family members had to fulfill the same diagnostic criteria that was applied to our patients.

\section{Results}

\section{Characteristics of our patients with familial ITP}

A total of 16 patients with familial ITP, from 8 families, were included in the study. All of the patients were Caucasian. A summary of the data is described in Table 1. In all families, 2 members were affected. The family relationships were mostly between a parent and a child. In family $G$ there was another member with immune pseudothrombocytopenia. In some families (B, D, E) there were other family members (between 1 and 5) with 
Table 1. Main characteristics of a case series of patients with familial immune thrombocytopenia

\begin{tabular}{|c|c|c|c|c|c|c|c|c|c|c|c|c|c|}
\hline \multirow[t]{2}{*}{ Family } & \multirow[t]{2}{*}{ Case } & \multirow[t]{2}{*}{ Age } & \multirow[t]{2}{*}{ Sex } & \multirow[t]{2}{*}{ Kinship } & \multirow{2}{*}{$\underset{\mathrm{a}}{\text { Bleeding }}$} & \multicolumn{2}{|c|}{ Pt counts ${ }^{b}$} & \multicolumn{2}{|c|}{$\underset{c}{\text { Pt morphology }}$} & \multirow[t]{2}{*}{$\begin{array}{l}\text { Diagnostic } \\
\text { criteria }^{\text {d }}\end{array}$} & \multirow[t]{2}{*}{$\lg e$} & \multirow{2}{*}{$\begin{array}{l}\text { Associated AD } \\
\text { autoimmune disorders }\end{array}$} & \multirow{2}{*}{$\begin{array}{c}\text { Associated } \\
\text { AM }^{\mathrm{g}}\end{array}$} \\
\hline & & & & & & E & M & Agg & Giant \% & & & & \\
\hline$A$ & 1 & 17 & $\mathrm{~F}$ & proband & no & 85 & 88 & - & 0 & Pt-AA & MA & & ANA \\
\hline A & 2 & 52 & $M$ & uncle & no & 64 & 90 & \pm & 0 & Pt-AA & G & & ANA \\
\hline B & 3 & 23 & $\mathrm{~F}$ & proband & $\mathrm{EB}, \mathrm{MB}$ & 35 & 93 & \pm & 8 & Pt-Kin & - & & \\
\hline B & 4 & 53 & $\mathrm{~F}$ & mother & no & 59 & 120 & \pm & 0 & Pt-AA & GM & Sjögren S (simultaneous) & \\
\hline C & 5 & 42 & $\mathrm{~F}$ & proband & EB & 50 & 75 & + & 20 & TR & - & & \\
\hline C & 6 & 17 & $\mathrm{~F}$ & daughter & no & 48 & 65 & + & 27 & Pt-AA & G & Graves D (before) & \\
\hline D & 7 & 45 & $\mathrm{~F}$ & proband & $\mathrm{EB}$ & 82 & 98 & \pm & 0 & Pt-AA & GM & SLE (after), Graves D (after) & \\
\hline D & 8 & 22 & $\mathrm{~F}$ & daughter & EB & 59 & 72 & - & 0 & Pt-AA & G & Hashimoto T (before), SLE (after) & APA \\
\hline $\mathrm{E}$ & 9 & 62 & M & proband & EB & 50 & 80 & \pm & 0 & Pt-AA & G & & \\
\hline$E$ & 10 & 48 & $\mathrm{~F}$ & sister & $\mathrm{EB}, \mathrm{MB}$ & 70 & 110 & ++ & 5 & Pt-AA & G & & \\
\hline $\mathrm{F}$ & 11 & 16 & $M$ & proband & EB & 40 & 42 & - & 0 & Pt-kinetics & - & & \\
\hline $\mathrm{F}$ & 12 & 22 & $\mathrm{~F}$ & sister & $\mathrm{CP}, \mathrm{MB}, \mathrm{SB}$ & 17 & 18 & \pm & 2 & Pt-AA,TR & G & CLE (after) & \\
\hline G & 13 & 28 & $\mathrm{~F}$ & proband & $\mathrm{Gi}$ & 50 & 76 & \pm & 35 & TR & - & & \\
\hline G & 14 & 50 & $\mathrm{~F}$ & mother & $\mathrm{EB}, \mathrm{Gi}, \mathrm{SB}$ & 75 & 120 & + & 17 & Pt-AA & GM & SLE (before), Graves D (before) & APA \\
\hline $\mathrm{F}$ & 15 & 35 & $M$ & proband & Ep & 15 & 44 & \pm & 7 & Pt-AA, TR & G & & \\
\hline $\mathrm{F}$ & 16 & 11 & $\mathrm{~F}$ & daughter & $\mathrm{CP}, \mathrm{Gi}$ & 1 & 3 & - & 1 & TR & nd & vitiligo (after) & \\
\hline
\end{tabular}

a Bleeding: no = no clinical bleeding, $\mathrm{EB}=$ easy bruising, $\mathrm{MB}=$ menstrual bleeding, $\mathrm{CP}=$ cutaneous purpura,

$\mathrm{SB}=$ surgical bleeding, $\mathrm{Gi}=$ gingivorrhagia, $\mathrm{Ep}=$ epistaxis

${ }^{b} \mathrm{Pt}$ counts = platelet counts $\times 10^{\circ} / \mathrm{L}$ : $\mathrm{E}=$ by electronic counters, $\mathrm{M}=$ by microscopy

${ }^{\mathrm{C}} \mathrm{Pt}$ morphology $=$ platelet morphology on blood films: Agg = platelet aggregates, Giant $\%=$ giant platelets $\%$

${ }^{\mathrm{d}}$ Diagnostic criteria applied: Pt-AA = platelet autoantibodies, Pt-kinetics = platelet kinetic study showing short platelet

survival,

$T R=$ therapeutic response to immunosupressors or splenectomy

${ }^{\mathrm{e}} \mathrm{Ig}=\mathrm{Ig}$ class found on the eluate of the platelet serologic study by immunofluorescence: $-=$ Ig not found, $\mathrm{nd}=\mathrm{Ig}$ not determined

${ }^{f}$ Associated $A D=$ associated autoimmune disorder; in brackets it is indicated if the AD was simultaneous or it appeared

before or after de onset of the ITP: Sjögren S = Sjögren syndrome, Graves D = Graves disease, Hashimoto T = Hashimoto

thyroiditis,

$\mathrm{SLE}=$ systemic lupus erythematosus, $\mathrm{CLE}$ = cutaneous lupus erythematosus

${ }^{\mathrm{g}}$ Associated $\mathrm{AM}=$ isolated autoimmune markers without clinical manifestations: $\mathrm{ANA}=$ antinuclear antibodies;

$\mathrm{APA}=$ antiphospholipid antibodies

thrombocytopenia of unknown origin. The median age of the patients was 31.5 years and the ratio women:men was 3:1. The patients had different bleeding manifestations mainly easy bruising or other types of mucocutaneous bleeding. The mean electronic platelet count was $50 \times 10^{9} / \mathrm{L}$ (standard deviation 24) and the mean microscopic platelet count was $75 \times 10^{9} / \mathrm{L}$ (standard deviation 34). Few and small platelet aggregates were observed in blood films of most patients. The presence of giant platelets was observed in approximately half of patients. The immunofluorescence tests revealed autoantibodies in the eluates of 10 patients (62.5\%), mainly of IgG type sometimes combined with IgM type. In cases 1, 6 and 9, in addition to the autoantibodies, we detected EDTA-dependent cryptoantibodies of the same Ig type (data not shown).

Three patients with clinical bleeding and platelet counts below $20 \times 10^{9} / \mathrm{L}$ needed to be treated with corticosteroids, alone or associated with intravenous IgG and/or rituximab. Among them, cases 15 and 16 showed improved platelet counts after treatment with corticosteroids. Case $12 \mathrm{did}$ not respond and later was successfully splenectomized. Other 2 patients (cases 5 and 13) were treated transiently with corticosteroids and responded with increases in platelet counts.

Besides ITP, 7 patients (43.7\%) also suffered from one or more associated $\mathrm{AD}$ (Table 1). The $\mathrm{AD}$ affecting thyroid function and lupus erythematosus were the most frequently found. These AD appeared before the onset of ITP, simultaneously, or after the ITP. Some patients had antinuclear antibodies, but without clinical manifestations of lupus and others had antiphospholipid antibodies without antiphospholipid syndrome. Lymphocyte counts and serum immunoglobulin levels were within normal límits except for case 6 where a slight increase in IgE was observed (data not shown).

\section{Literature review on familial ITP}

We found 60 cases of familial ITP in 20 families, reported in 20 articles ${ }^{6-25}$. The results are summarized in Supplementary Table 1. Most families had 2 members 
affected and the other families had 3, 4, 5, and even 6 members affected. The familial relationships were between brothers and sisters in 13 families, including twins ( 1 family), monozygotic twins (4 families), and a combination of 2 monozygotic twins and 1 sister ( 1 family). Five families had several affected members with different kinship degrees and 2 families had both parents and children affected. Most patients were Caucasian but also Black $^{13}$, Chinese ${ }^{22}$, and Arabic ${ }^{18,23}$. Moreover, the 2 families reported by Ahmed et al. ${ }^{18,23}$ had some consanguineous marriages. The ages of patients were between 14 months and 85 years, with a median of 17 years. There were 37 women and 23 men (ratio women: men 1.7:1). The bleeding manifestations were diverse ranging from no bleeding to intracranial hemorrhage passing through different degrees of mucocutaneous bleeding. The platelet counts were diverse also, from 3 to $114 \times 10^{9} / \mathrm{L}$ (mean 42, standard deviation 33). The platelet counts often varied over time in the same patient. We could not find a description of platelet morphology except the observation of large platelets in the patients reported by Bizzaro ${ }^{15}$ and in one of the patients (case 2 ) reported by Roganovic ${ }^{25}$. The positive diagnostic criteria for ITP applied were the therapeutic response with immunosuppressors and/or the detection of antibodies on the platelet surface in most cases. Only in 3 patients, the criterion was a short platelet survival in the isotopic kinetic study.

Different types of associated $\mathrm{AD}$ were described in 20 patients (33.3\%). In all of them only one $\mathrm{AD}$ was detected, except in one patient who was 2 associated AD. Autoimmune hemolytic anemia was the AD most freqüent; it was reported in 9 patients from 4 families. Other types of associated $\mathrm{AD}$ found were lupus erythematosus, Graves disease, immune neutropenia, antiphospholipid syndrome, celiac disease and psoriasis. Most AD were diagnosed at the same time as ITP (11 AD) and they appeared less frequently before ( $3 \mathrm{AD}$ ) or after ( $5 \mathrm{AD}$ ) the onset of the ITP; for $2 \mathrm{AD}$ the timing of onset was not reported. Isolated autoimmune markers without clinical manifestations such as antinuclear antibodies and/or double-stranded DNA antibodies were found in 2 families without clinical lupus. Antiphospholipid antibodies without antiphospholipid syndrome were found in 2 patients from 2 families.

Some families also presented comorbid non-immune disorders. Two consanguineous families suffered from hereditary spastic paraplegia ${ }^{18}$ and from joint hypermobility and mitral valve regurgitation ${ }^{23}$. The factor $V$ Leiden was found in several members of 2 families ${ }^{19,20}$. In one of these families ${ }^{19}$, the confluence of antiphospholipid syndrome with factor $\mathrm{V}$ Leiden contributed to the presentation of thrombosis even though they had low platelet counts; some individuals in this family had also migraine, leukocytosis and/or polycythemia.

\section{Discussion}

Because we attended many thrombocytopenic patients grouped in families, we were able to study 16 patients with familial ITP. In addition, we studied 60 patients with familial ITP reported in the literature.

\section{Incidence of familial ITP}

As far as we know, there is no study published on the incidence of familial ITP. In 2011, the PARC Registry on ITP ${ }^{3}$ estimated that $2 \%$ of children and $3 \%$ of adults with ITP had other family members with thrombocytopenia. Although some of these thrombocytopenias could be immune-mediated, the precise proportion of ITP in these families was not reported.

The first article on ITP cited in PubMed was from January $1916^{26}$, although an indetermined number of articles had been previously published. Over the last 102 years we have detected only 76 patients with familial ITP, including our 16 patients. According to these data we can estimate the annual incidence of familial ITP around 0.74 cases/year. It is a very low incidence when compared to the general incidence of ITP, estimated between 1.9 and $6.4 \mathrm{x}$ 105 cases/year ${ }^{27}$.

\section{General characeristics of familal ITP}

In our families with ITP, the parent-child relationship was the most freqüent, whereas in the published families the predominant relationship was among brothers and sisters including a high number of twins. It has been assumed that sporadic ITP occurs at any age, with a preponderance in childhood and in old age ${ }^{3,28-33}$. Also, it has been estimated that the frequency of ITP is higher in women in the mid-adult years, whereas in the rest of ages the frequency is equal in both sexes ${ }^{3,29-31,34}$. Our patients and those reported in the literature with familial ITP had ages and sex distribution more or less the same as previously described in sporadic ITP. However, patients in the published literature had a lower median age in contrast to our patients. This could explain, in part, the lower ratio women:men found in the published reports. Likewise, the type of bleeding in patients with familial ITP was similar to that described in sporadic ITP, that is, predominance of cutaneous-mucosal forms and heterogeneous intensity of bleeding ${ }^{3,29-33,35}$. Platelet counts were highly heterogeneous in patients with familial ITP, as well as those generally described in sporadic ITP ${ }^{3,28,33,35}$. In the familial ITP patients reported, the mean platelet counts were lower and with a greater dispersion than in our patients.

\section{Associated autoimmune disorders in familial ITP}

More than $40 \%$ of our patients had an associated AD (Table 1). Five of these patients (cases 6, 7, 8, 12, 14) were included in a previous study on shared autoimmunity 
${ }^{36}$. About one third of the familial ITP patients previously reported also had associated AD (Supplementary Table 1). Although there is no study of the global incidence of associated $\mathrm{AD}$ in ITP, there are studies on the incidence of some specific AD (revisited in-Segal and Powe, 2006) ${ }^{37}$. The incidence of associated AD in the 76 familial ITP patients in our study (own cases together with published cases) was higher than in sporadic ITP patients. For exemple, the incidence of lupus has been estimated as $3.1 \%$ in sporadic ITP but in our study the incidence reached $6.6 \%$. Autoimmune hemolytic anemia $(0.9 \%$ in sporadic ITP and $11.8 \%$ in our study) and AD affecting thyroid gland (1.1\% in sporadic ITP and $7.9 \%$ in our study) are other examples. Unlike other studies on general ITP series ${ }^{36-37}$ we found a high proportion of hemolytic anemias, mainly in the familial ITP patients previously published. These anemias, as well as the immune neutropenias, tended to be initiated at the same time as the ITP like those described in sporadic ITP ${ }^{36}$. However, the other types of associated AD tended to be initiated before of after the onset of the ITP. As we stated in a previous article ${ }^{36}$ and according to the suggestion of other authors ${ }^{3}$, we consider that the term "secondary ITP" in the consensus reports ${ }^{1}$ should be reconsidered. The fact that the associated AD can appear indistinctly before, after or simultaneously with ITP, suggests a common cause leading to both conditions. The association of ITP with other AD is likely due to an overlap or "shared autoimmunity" caused by the interaction between genetic and environmental factors ${ }^{38-39}$.

\section{Diagnostic aspects}

It is notable that, over 28 years, our center was able to diagnose 16 patients with familial ITP while in all published articles, over more than 102 years, only 60 familial ITP patients have been reported. It is possible that this discordance may be due to the familial presentation of the thrombocytopenia leading to the misdiagnosis of genetic thrombocytopenia instead of familial ITP.

The first steps in the diagnosis of ITP are to confirm the thrombocytopenia and to discard all of the exclusion criteria for ITP. To improve the diagnostic efficiency of ITP, the most used guidelines recommend to evaluate the peripheral blood films ${ }^{34}$. As a result, the misdiagnosis of genetic platelet disorders with giant platelets and pseudothrombocytopenia would be reduced. In our series, we performed microscopic platelet counts in addition to electronic counts (Table 1). We found that microscopic counts were higher as it accounts in general laboratory practice ${ }^{40-41}$. We observed platelet aggregates in some patients. Given that the platelet aggregates were generally few and small, and the thrombocytopenia persisted in the microscopic counts, the diagnosis of pseudotrombocitopenia was ruled out. The presence of large platelets is not rare in ITP. This could be due to the increase in young platelets ${ }^{42-43}$. Giant platelets were prominent in blood films of patients from our families $\mathrm{C}$ and $\mathrm{B}$. Therefore, we performed genetic studies and were able to exclude the diagnosis of MYH9-related disorder and Bernard-Soulier syndrome.

In the presence of thrombocytopenia without specific features, ITP is usually diagnosed by exclusion of other causes of thrombocytopenia $1,29,44$. However, if we only apply exclusion criteria, we could not disintinguish patients who have a familial ITP from patients who have a genetic thrombocytopenia with no apparent specific traits such as the thrombocytopenia related to mutations in ANKRD26 gene or in RUNX1 gene ${ }^{45}$.

In our study, we required positive criteria before concluding whether the patients we studied and those reported in the literature really had ITP. One of the positive criteria was the finding of autoantibodies on the platelet surface. The consensus reports on ITP do not include the antiplatelet antibody assays in the "basic evaluation" for the diagnosis; they are considered only of "potential utility" ${ }^{34}$. However, wethought that when we couldfind autoantibodies in the surface of platelets it had a great diagnostic value, especially if it was combined with clinical bleeding ${ }^{46}$. The finding of cryptoantibodies together with autoantibodies can occur in some patients with ITP. However, there is no confusion with pseudothrombocytopenia when proving that the thrombocytopenias persists in microscopic counts.

Another positive criteria was the shortening of platelet survival in isotopic kinetic studies. In the consensus reports, the platelet survival study was classified as a "test of unproven or uncertain benefit", but without any explanation to support this statement ${ }^{34}$. We considered that a shortened platelet survival in patients with negative antiplatelet antibodies was essential to establish the diagnosis of ITP. The kinetic study allowed also to evaluate the platelet turnover and the main site of platelet destruction ${ }^{47}$. The third positive criterion was a clear response to immunosuppressor treatment or splenectomy. Any thrombocytopenia secondary to a nonautoimmune cause would not respond or would do so in a weak and transient manner.

\section{Limitations of the study}

We did not pretend that the present study had epidemiological value due to the bias on the enrollment of our patients that could lead to an erroneous increased frequency of familial ITP. Moreover, the patients described in the publisehd articles were reported over a long period of time. Also, they came from different countries and ethnicities. Therefore, they are not an appropriate sample from the epidemiological point of view. Despite these limitations, we think that is useful to draw attention to the familial forms of ITP and to analyze their specific characteristics, as well as, to improve their detection. 


\section{Conclusions}

To improve the underdiagnosis of familial ITP, we propose, firstly, to consider the existence of this disease when a familial thrombocytopenia has no demonstrable genetic cause, especially if the family has features of autoimmunity. Secondly, the need to use additional positive criteria (platelet autoantibodies, short platelet survival, therapeutic response), besides the exclusion diagnostic criteria to confirm the diagnosis of familial ITP.

\section{Author's Contributions}

NPM and EMD coordinated the research. NPM and JCS selected the patients and families that met criteria for familial immune ITP from the medical records of the center and from the literature review. BJ designed and filled out a database with all data of the selected patients. EMD and MR revised, respectively, the platelet autoantibodies tests and the platelet kinetic studies, when performed. NPM wrote the article and all authors reviewed the manuscript and approved its final version.

\section{Acknowledgement}

The authors wish to thank Professor William Stone (University of Wisconsin) for reviewing the manuscript.

\section{References}

1. Rodeghiero F, Stasi R, Gernsheimer T, et al. Standardization of terminology, definitions and outcome criteria in immune thrombocytopenic purpura of adults and children: report from an international working group. Blood. 2009; 113(11): 2386-2393.

2. Stasi R. Immune thrombocytopenia: pathophysiologic and clinical update. Semin Thromb Hemost. 2012; 38(5): 454-462.

3. Kühne T, Berchtold W, Michaels LA, et al. Intercontinental Cooperative ITP Study Group. Newly diagnosed immune thrombocytopenia in children and adults: a comparative prospective observational registry of the Intercontinental Cooperative Immune Thrombocytopenia Study Group. Haematologica. 2011; 96(12): 1831-1837.

4. von dem Borne AE, Helmerhorst FM, van Leeuwen EF, et al Autoimmune thrombocytopenia: detection of platelet autoantibodies with the suspension immunofluorescence test. Br J Haematol. 1980; 45(2): 319-327.

5. Muñiz-Diaz E, Madoz P, Pujol-Moix N, et al. Characterization of antibodies directed against platelet cryptantigens detected during the immunological study of 356 consecutive patients with presumed autoimmune thrombocytopenia (AITP). Transfus Med. 1995; 5(3): 185-191.

6. De Spirito A. Thrombocytopenic purpura in twins. Clin Proc Child Hosp Dist Columbia. 1953; 9(12): 256-261.

7. Shaar FE. Familial idiopathic thrombocytopenic purpura. J Pediatr. 1963; 62(Apr): 546-551.

8. Harms D, Sachs V. Familial chronic thrombocytopenia with platelet autoantibodies. Acta Haematol. 1965; 34(1): 30-35.

9. Norris AD. Idiopathic thrombocytopenic purpura in identical twins. Br J Clin Pract. 1973; 27(3): 95-97.

10. Stuart MJ, Tomar RH, Miller ML, et al. Chronic idiopathic thrombocytopenic purpura. A familial immunodeficiency síndrome. JAMA. 1978; 239(10): 939-942.
11. Msefer-Alaoui F, Bouaouda H, Lahrichi $H$, et al. Purpura thrombopénique idiopathique familial. Ann Pediatr (Paris). 1981; 28(3): 215-220.

12. Karpatkin S, Fotino M, Winchester R. Hereditary autoimmune thrombocytopenic purpura: an immunologic and genetic study. Ann Intern Med 1981; 94(6): 781-782.

13. Laster AJ, Conley CL, Kickler TS, et al. Chronic immune thrombocytopenic purpura in monozygotic twins: genetic factors predisposing to ITP. N Engl J Med 1982; 307(24): 1495-1498.

14. Bogart L, Wittels EG. Idiopathic thrombocytopenic purpura in two elderly siblings. Arch Intern Med. 1985; 145(12): 2259.

15. Bizzaro N. Familial association of autoimmune thrombocytopenia and hyperthyroidism. Am J Hematol. 1992; 39(4):294-298.

16. Shimizu K, Katsuta I, Uchikawa T. Familial lupoid thrombocytopenia. Am J Hematol. 1993; 44(1): 9-11.

17. Sanchez Fayos J, Olavarría E, Román A, et al. Púrpura trombocitopénica idiopática en cinco miembros de una familila [Idiopathic hrombocytopenic purpura in 5 members of a family]. Sangre (Barc). 1994; 39(3): 215-217.

18. Ahmed FE, Qureshi IM, Wooldridge MA, et al. Hereditary spastic paraplegia and Evans's syndrome. Acta Paediatr. 1996; 85(7): 879881.

19. Schütt M, Klüter H, Hagedorn-Greiwe $M$, et al. Familial coexistence of primary antiphospholipid syndrome and factor V Leiden. Lupus. 1998; 7(3): 176-182.

20. McLeod AG, Pai M, Carter RF, et al. Familial Evans syndrome: a report of an affected sibship. J Pediatr Hematol Oncol 1999; 21(3): 244-247.

21. Patel AP. Idiopathic autoimmune thrombocytopenia and neutropenia in siblings. Eur J Haematol. 2002; 69(2): 120-121.

22. Huang WC, Lien SH, Chang DM, et al. Monozygotic twins concordant for idiopathic thrombocytopenic purpura and discordant for systemic lupus erythematosus and lupus nephritis. Eur J Pediatr. 2007; 166(5): 497-500.

23. Ahmed FE, Albakrah MS. Neonatal familial Evans syndrome associated with joint hypermobility and mitral valve regurgitation in three siblings in a Saudi Arab family.

24. Ann Saudi Med 2009; 29(3): 227-230.

25. Ruades Ninfea JI, Basquiera $\mathrm{AL}$, Tabares $\mathrm{AH}$, et al. Immune thrombocytopenia with antiphospholipid antibodies in monozygotic twins. Platelets. 2012; 23(4): 309-311.

26. Roganovic J. Celiac disease with Evans syndrome and isolated immune thrombocytopenia in monozygotic twins: a rare association. Semin Hematol. 2016; 53(Suppl 1): S61-S63.

27. Lee RI, Robertson $\mathrm{OH}$. The effect of antiplatelet serum on blood platelets and the experimental production of purpura hemorrhagica. J Med Res. 1916; 33(3): 323-336.

28. Terrell DR, Beebe LA, Vesely SK, et al. The incidence of immune thrombocytopenic purpura in children and adults: A critical review of published reports. Am J Hematol. 2010; 85(3): 174-180.

29. Kurata Y, Fujimura K, Kuwana M, et al. Epidemiology of primary immune thrombocytopenia in children and adults in Japan: a population-based study and literature review. Int J Hematol. 2011; 93(3): 329-335.

30. Kistangari G, McCrae KR. Immune thrombocytopenia. Hematol Oncol Clin North Am. 2013; 27(3): 495-520.

31. Grimaldi-Bensouda L, Nordon C, Michel M, et al. Group for the PGRxITP Study. Immune thrombocytopenia in adults: a prospective cohort study of clinical features and predictors of outcome. Haematologica. 2016; 101(9): 1039-1045. 
32. Altomare I, Cetin K, Wetten S, et al. Rate of bleeding-related episodes in adult patients with primary immune thrombocytopenia: a retrospective cohort study using a large administrative medical claims database in the US. Clin Epidemiol. 2016; 8(Jun 20): 231-239.

33. Moulis G, Germain J, Comont T, et al. CARMEN Investigators Group. Newly diagnosed immune thrombocytopenia adults: Clinical epidemiology, exposure to treatments, and evolution. Results of the CARMEN multicenter prospective cohort. Am J Hematol. 2017; 92(6): 493-500.

34. Zufferey A, Kapur R, Semple JW. Pathogenesis and Therapeutic Mechanisms in Immune Thrombocytopenia (ITP). J Clin Med. 2017; 6(2). E16.

35. Provan D, Stasi R, Newland AC, et al. International consensus report on the investigation and management of primary immune thrombocytopenia. Blood. 2010; 115(2): 168-186.

36. Swinkels M, Rijkers M, Voorberg J, et al. Emerging Concepts in Immune Thrombocytopenia. Front Immunol. 2018; 9(Apr 30): 880.

37. Díaz-Polo LE, Pujol-Moix N, Jiménez B, et al. Shared autoimmunity: A case series of 56 patients with immune thrombocytopenia (ITP) associated with other autoimmune disorders. Open Acces Library Journal. 2016, 3(Aug 3): e2807.

38. Segal JB, Powe NR. Prevalence of immune thrombocytopenia: analyses of administrative data. J Thromb Haemost. 2006; 4(11): 2377-2383.

39. Cheung E, Liebman HA. Thyroid disease in patients with immune thrombocytopenia. Hematol Oncol Clin North Am. 2009; 23(6): 12511260.

40. Mackay IR. Clustering and commonalities among autoimmune diseases. J Autoimmun. 2009; 33(3-4): 170-177.
41. Pujol-Moix N, Martínez A, García-Dabrio C, et al. Análisis de los parámetros plaquetarios en una muestra de población española, con variaciones metodológicas específicas para reducir la infravaloración de las plaquetas macrocíticas. Haematologica. 2008; 93(Extra 2): 125.

42. Diquattro M, Gagliano F, Calabrò GM, et al. Relationships between platelet counts, platelet volumes and reticulated platelets in patients with ITP: evidence for significant platelet count inaccuracies with conventional instrument methods. Int J Lab Hematol. 2009; 31(2): 199-206.

43. Kaito K, Otsubo H, Usui N, et al. Platelet size deviation width, platelet large cell ratio, and mean platelet volume have sufficient sensitivity and specificity in the diagnosis of immune thrombocytopenia. $\mathrm{Br} \mathrm{J}$ Haematol. 2005; 128(5): 698-702.

44. Noris P, Biino G, Pecci A, et al. Platelet diameters in inherited thrombocytopenias: analysis of 376 patients with all known disorders. Blood. 2014; 124(6): e4-e10.

45. Consolini R, Costagliola G, Spatafora D. The Centenary of Immune Thrombocytopenia-Part 2: Revising Diagnostic and Therapeutic Approach. Front Pediatr. 2017; 5(Aug 21): 179.

46. Noris P, Balduini CL. Inherited thrombocytopenias in the era of personalized medicine. Haematologica. 2015; 100(2): 145-148.

47. Muñiz-Diaz E, Pujol-Moix N, Canals C, et al. The role of bleeding and platelet antibodies in assessing the immune diagnosis of primary suspected immune thrombocytopenias. Vox Sanguinis. 2006; 91(Suppl 2), 22.

48. Roca M, Muñiz-Diaz E, Mora J, et al. The scintigraphic index spleen/ liver at 30 minutes predicts the success of splenectomy in persistent and chronic primary immune thrombocytopenia. Am J Hematol. 2011; 86(11): 909-913. 
Supplementary Table 1. Main characteristics of the patients with familial immune thrombocytopenia reported in the literature

\begin{tabular}{|c|c|c|c|c|c|c|c|c|c|}
\hline Family $^{a}$ & Case $^{b}$ & Age $^{c}$ & Sex $^{d}$ & Kinship & Bleeding $^{e}$ & Pt counts ${ }^{f}$ & $\begin{array}{l}\text { Diagnostic } \\
\text { criteria }^{\mathrm{g}}\end{array}$ & Associated AD ${ }^{h}$ & $\begin{array}{c}\text { Associated } \\
\text { AM }^{i}\end{array}$ \\
\hline \multirow{2}{*}{ De Spirito, $1953^{6}$} & R.H. & $21 \mathrm{~m}$ & M & proband & CP,Ep,Ot & 10 & TR & & \\
\hline & M.H. & $21 \mathrm{~m}$ & M & twin & CP, Ep & 10 & TR & & \\
\hline \multirow{4}{*}{ Shaar, $1963^{7}$} & J. & 2 & M & proband & $\mathrm{CP}$ & 36 & TR & & \\
\hline & M. & 2 & $M$ & brother & $\mathrm{CP}$ & 94 & TR & & \\
\hline & D. & $14 \mathrm{~m}$ & M & brother & $\mathrm{CP}$ & 23 & TR & & \\
\hline & J.S.C. & $18 \mathrm{~m}$ & M & brother & $\mathrm{CP}$ & 18 & TR & & \\
\hline \multirow{5}{*}{ Harms and Sachs, $1965^{8}$} & 4 R.W. & 19 & $\mathrm{~F}$ & proband & EB & $24-40$ & Pt-AA & & \\
\hline & 5 U.W. & 16 & $\mathrm{~F}$ & sister & $\mathrm{EB}, \mathrm{Ep}$ & $15-54$ & Pt-AA & & \\
\hline & 6 G.W. & 12 & $\mathrm{~F}$ & sister & no & 60 & Pt-AA & & \\
\hline & 3 H.W. & 43 & $\mathrm{~F}$ & mother & no & 120 & Pt-AA & & \\
\hline & 1 A.B. & 74 & $\mathrm{~F}$ & grandmother & EB & 87 & Pt-AA & & \\
\hline \multirow{2}{*}{ Norris, $1973^{9}$} & Case 1 & 17 & $\mathrm{~F}$ & proband & EB,Ep,MB,BT & $<5$ & TR & & \\
\hline & Case 2 & 20 & $\mathrm{~F}$ & mono twin & $\mathrm{CP}$ & 50 & TR & & \\
\hline \multirow{2}{*}{$\begin{array}{l}\text { Stuart et al, } 1978^{10} \\
\text { (family } 3 \text { only) }\end{array}$} & Case 1 & 2 & M & proband & $\mathrm{CP}$ & 20 & Pt-kinetics & & \\
\hline & Case 2 & 24 & $M$ & father & no & 101 & Pt-kinetics & & \\
\hline \multirow{2}{*}{$\begin{array}{l}\text { Msefer-Alaoui et al, } \\
1981^{11} \text { (except case } \text { IV }_{5} \text { ) }\end{array}$} & $\mathrm{IV}_{6}$ & 12 & M & proband & $\mathrm{CP}, \mathrm{Ep}, \mathrm{SB}$ & 5 & TR & & \\
\hline & $\mathrm{IV}_{1}$ & 6 & $\mathrm{~F}$ & sister & $\mathrm{EB}, \mathrm{Ep}, \mathrm{GIB}$ & 40 & Pt-kinetics & & \\
\hline \multirow{4}{*}{ Karpatkin et al, $1981^{12}$} & $\mathrm{I}: 2$ & 63 & $\mathrm{~F}$ & proband & $\mathrm{OB}, \mathrm{SB}$ & $60-80$ & Pt-AA,TR & & \\
\hline & $\mathrm{II} 1$ & 29 & M & son & $\mathrm{EB}, \mathrm{BT}$ & $20-40$ & Pt-AA & & \\
\hline & $\|: 2$ & 36 & $\mathrm{~F}$ & daughter & EB & $30-64$ & Pt-AA & & \\
\hline & $11: 3$ & 25 & $\mathrm{~F}$ & daughter & $\mathrm{EB}$ & $55-107$ & Pt-AA & & \\
\hline \multirow{3}{*}{ Laster et al, $1982^{13}$} & 1112 & 14 & $\mathrm{~F}$ & proband & $\mathrm{CP}, \mathrm{MB}$ & 3 & Pt-AA,TR & & ssDNA \\
\hline & III1 & 15 & $\mathrm{~F}$ & mono twin & $\mathrm{CP}$ & 14 & Pt-AA,TR & & ssDNA,ANA \\
\hline & 1113 & 18 & $\mathrm{~F}$ & sister & no & $85-98$ & Pt-AA & & ssDNA \\
\hline \multirow{2}{*}{$\begin{array}{l}\text { Bogart and Wittels, } \\
1985^{14}\end{array}$} & Case 1 & 77 & M & proband & $\mathrm{CP}$ & 3 & Pt-AA,TR & & \\
\hline & Case 2 & 80 & $\mathrm{~F}$ & sister & $\mathrm{CP}$ & 80 & Pt-AA,TR & & \\
\hline \multirow{4}{*}{ Bizzaro, $1992^{15}$} & Case 1 & 35 & $\mathrm{~F}$ & proband & Ep & 47 & Pt-AA & & \\
\hline & Case 2 & 38 & $\mathrm{~F}$ & sister & no & $82-92$ & Pt-AA & Graves D (after) & \\
\hline & Case 3 & 23 & $\mathrm{~F}$ & sister & no & 96 & Pt-AA & & \\
\hline & Case 4 & 59 & $\mathrm{~F}$ & mother & no & 93 & Pt-AA & Graves D (after) & \\
\hline \multirow{3}{*}{ Shimizu et al, $1993^{16}$} & II:6 & 27 & $\mathrm{~F}$ & proband & $\mathrm{CP}, \mathrm{MB}$ & 44 & Pt-AA & & ANA \\
\hline & III:2 & 55 & $\mathrm{~F}$ & mother & EB & 77 & Pt-AA & & ANA,ssDNA \\
\hline & IV:1 & 4 & $\mathrm{~F}$ & daughter & $\mathrm{CP}$ & 38 & Pt-AA & & ANA \\
\hline \multirow{5}{*}{$\begin{array}{l}\text { Sanchez Fayos et al, } \\
1994^{17}\end{array}$} & Case 1 & 48 & $\mathrm{~F}$ & proband & CP,Ep,BT & 19 & Pt-AA,TR & & \\
\hline & Case 2 & 4 & $M$ & son & $\mathrm{CP}, \mathrm{Ep}$ & 9 & TR & & \\
\hline & Case 3 & 16 & M & brother & nd & low & TR & & \\
\hline & Case 4 & nd & $\mathrm{F}$ & sister & nd & low & TR & & \\
\hline & Case 5 & nd & $\mathrm{F}$ & niece & nd & low & $\mathrm{TR}$ & & \\
\hline \multirow{2}{*}{ Ahmed et al, $1996^{18}$} & AMA & 5 & M & proband & nd & 56 & $\mathrm{TR}$ & $\begin{array}{c}\text { AHA } \\
\text { (simultaneous) }\end{array}$ & \\
\hline & NMA & 2.5 & M & brother & nd & 23 & TR & $\begin{array}{c}\text { AHA } \\
\text { (simultaneous) }\end{array}$ & \\
\hline
\end{tabular}




\begin{tabular}{|c|c|c|c|c|c|c|c|c|c|}
\hline \multirow{6}{*}{ Schütt et al, $1998^{19}$} & $\mathrm{l}: 2$ & 85 & $\mathrm{~F}$ & proband & BT & $<50$ & Pt-AA & APS (not described) & \\
\hline & $\|: 2$ & 58 & $\mathrm{~F}$ & daughter & nd & $<50$ & Pt-AA & & \\
\hline & $11: 7$ & 54 & M & son & nd & $45-70$ & Pt-AA & APS (not described) & \\
\hline & II:9 & 45 & $\mathrm{~F}$ & daughter & nd & $70-114$ & Pt-AA & & APA \\
\hline & III:6 & 33 & $\mathrm{~F}$ & granddaughter & nd & $70-114$ & Pt-AA & & \\
\hline & IV:1 & 10 & M & $\begin{array}{l}\text { great- } \\
\text { grandson }\end{array}$ & nd & $70-114$ & Pt-AA & & \\
\hline \multirow{3}{*}{ McLeod et al, $1999^{20}$} & Patient A & $4 \mathrm{~m}$ & $\mathrm{~F}$ & proband & $\mathrm{CP}$ & 8 & $\mathrm{TR}$ & AHA (simultaneous) & \\
\hline & Patient B & 4 & M & brother & $\mathrm{CP}$ & 5 & $\mathrm{TR}$ & AHA (after) & \\
\hline & Patient C & 13 & M & brother & nd & 17 & TR & AHA (simultaneous) & \\
\hline \multirow{2}{*}{ Patel, $2002^{21}$} & & 35 & M & proband & $\mathrm{CP}$ & 36 & $\mathrm{TR}$ & INP (simultaneous) & \\
\hline & & 30 & M & brother & $C P, I C B$ & $10-30$ & $\mathrm{TR}$ & INP (simultaneous) & \\
\hline \multirow[t]{2}{*}{ Huang et al, 200722} & Twin 1 & 14 & $\mathrm{~F}$ & proband & $\mathrm{CP}$ & 18 & $\mathrm{TR}$ & SLE (simultaneous) & \\
\hline & Twin 2 & 12 & $\mathrm{~F}$ & mono-twin & $\mathrm{CP}$ & 24 & $\mathrm{TR}$ & SLE (simultaneous) & \\
\hline \multirow{3}{*}{$\begin{array}{l}\text { Ahmed and AlBakrah, } \\
2009^{23}\end{array}$} & Case 1 & $9 \mathrm{~m}$ & M & proband & $\mathrm{CP}, \mathrm{Ep}$ & 9 & $\mathrm{TR}$ & AHA (after) & \\
\hline & Case 2 & 3 & M & brother & $\mathrm{CP}, \mathrm{Ep}$ & 7 & $\mathrm{TR}$ & AHA (simultaneous) & \\
\hline & Case 3 & $18 \mathrm{~m}$ & $\mathrm{~F}$ & sister & CP, Ep & 7 & $\mathrm{TR}$ & AHA (simultaneous) & \\
\hline \multirow{2}{*}{$\begin{array}{l}\text { Ruades Ninfea et al, } \\
2012^{24}\end{array}$} & Case 1 & 61 & $\mathrm{~F}$ & proband & Ep & $16-71$ & TR & psoriasis (before) & APA \\
\hline & Case 2 & 63 & $\mathrm{~F}$ & mono-twin & EB & 7 & TR & APS (after) & \\
\hline \multirow[t]{2}{*}{ Roganovic, $2016{ }^{25}$} & Case 1 & 2.5 & $\mathrm{~F}$ & proband & $\mathrm{CP}$ & 19 & TR & $\begin{array}{c}\text { celiac D (before), } \\
\text { AHA (simultaneous) }\end{array}$ & \\
\hline & Case 2 & 6 & $\mathrm{~F}$ & mono-twin & $\mathrm{CP}$ & 19 & Pt-AA & celiac D (before) & \\
\hline
\end{tabular}

${ }^{a}$ Family = bibliographic reference of the family described

${ }^{b}$ Case: original identification of each family member in the article

'Age: the presence of " $\mathrm{m}$ " indicates that the age is expressed in months, otherwise it is expressed in years

dSex: $M=$ male, $F$ = female

${ }^{\mathrm{e}}$ Bleeding: $\mathrm{CP}=$ cutaneous purpura, $\mathrm{Ep}=$ epistaxis, $\mathrm{Ot}=$ otorrhagia, $\mathrm{EB}=$ easy bruising, no = no clinical bleeding,

$\mathrm{MB}=$ menstrual bleeding, $\mathrm{BT}=$ bleeding for trauma, $\mathrm{SB}=$ surgical bleeding, $\mathrm{GI}=$ = gastrointestinal bleeding,

$\mathrm{OB}=$ obstetric bleeding, $\mathrm{nd}=$ not described, $\mathrm{ICB}=$ intracranial bleeding

${ }^{\mathrm{f}} \mathrm{Pt}$ counts $=$ platelet counts $\times 10^{9} / \mathrm{L}$

${ }^{g}$ Diagnostic criteria. Data contained in the article supporting the diagnosis of ITP: TR = therapeutic response to immunosupressors or splenectomy, Pt-AA = platelet autoantibodies, Pt-kinetics = platelet kinetic study showing short platelet survival

${ }^{\mathrm{h}}$ Associated $A D=$ associated autoimmune disorder; in brackets it is indicated if the $A D$ was simultaneous or it appeared before or after de onset of the ITP: Graves D = Graves disease, AHA = autoimmune hemolytic anemia, APS = antiphospholid syndrome, INP = immune neutropenia, SLE = systemic lupus erythematosus,

' Associated AM = isolated autoimmune markers without clinical manifestations: ssDNA = single-stranded anti-DNA antibodies, ANA = antinuclear antibodies, $\mathrm{APA}=$ antiphospholipid antibodies 